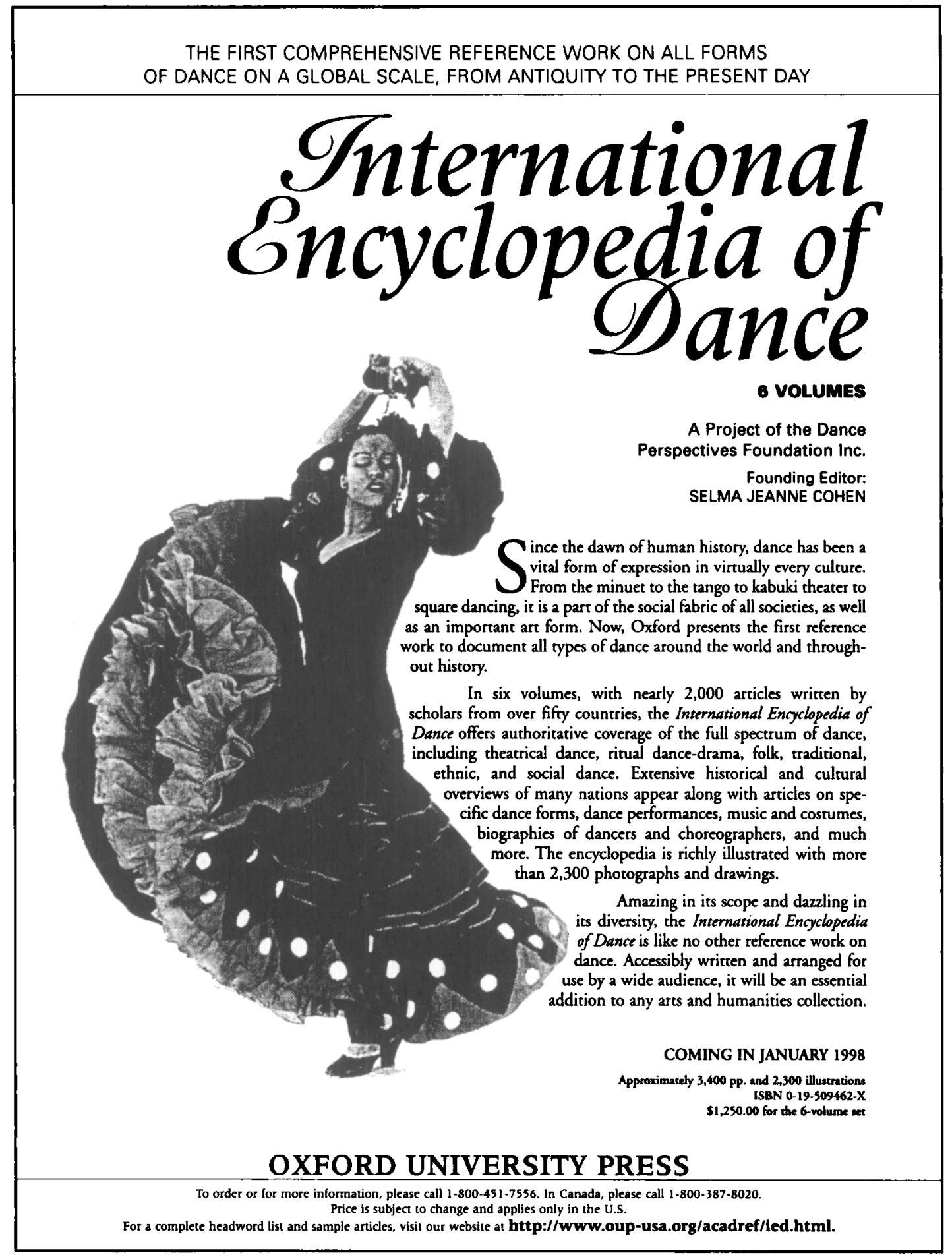




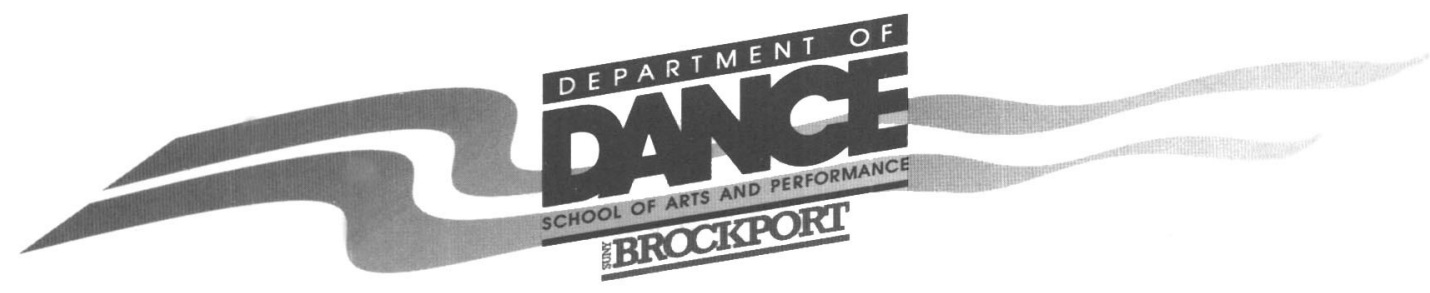

\section{Department of Dance}

Degrees in Dance

B.A./B.S.

B.F.A.*

B.F.A. teacher certification $k-12 *$

M.A.

M.F.A.*

\section{Emphasis Areas}

Performance

Choreography

Dance Science/Somatics

African Dance/Music

Music in Dance

Dance in Education

\section{Special Features}

Distinguished Faculty

500-seat Dance Theater

Six Dance Studios

Bodywork Conditioning Studio

Two Touring Companies

Computer Labs for Sound Scores and Lighting Design

Study Abroad and Exchange Programs in England, Brazil, Ghana, Jamaica, and Japan

Professional Internships and Apprenticeships

Numerous Guest Artists

*Degree approval pending

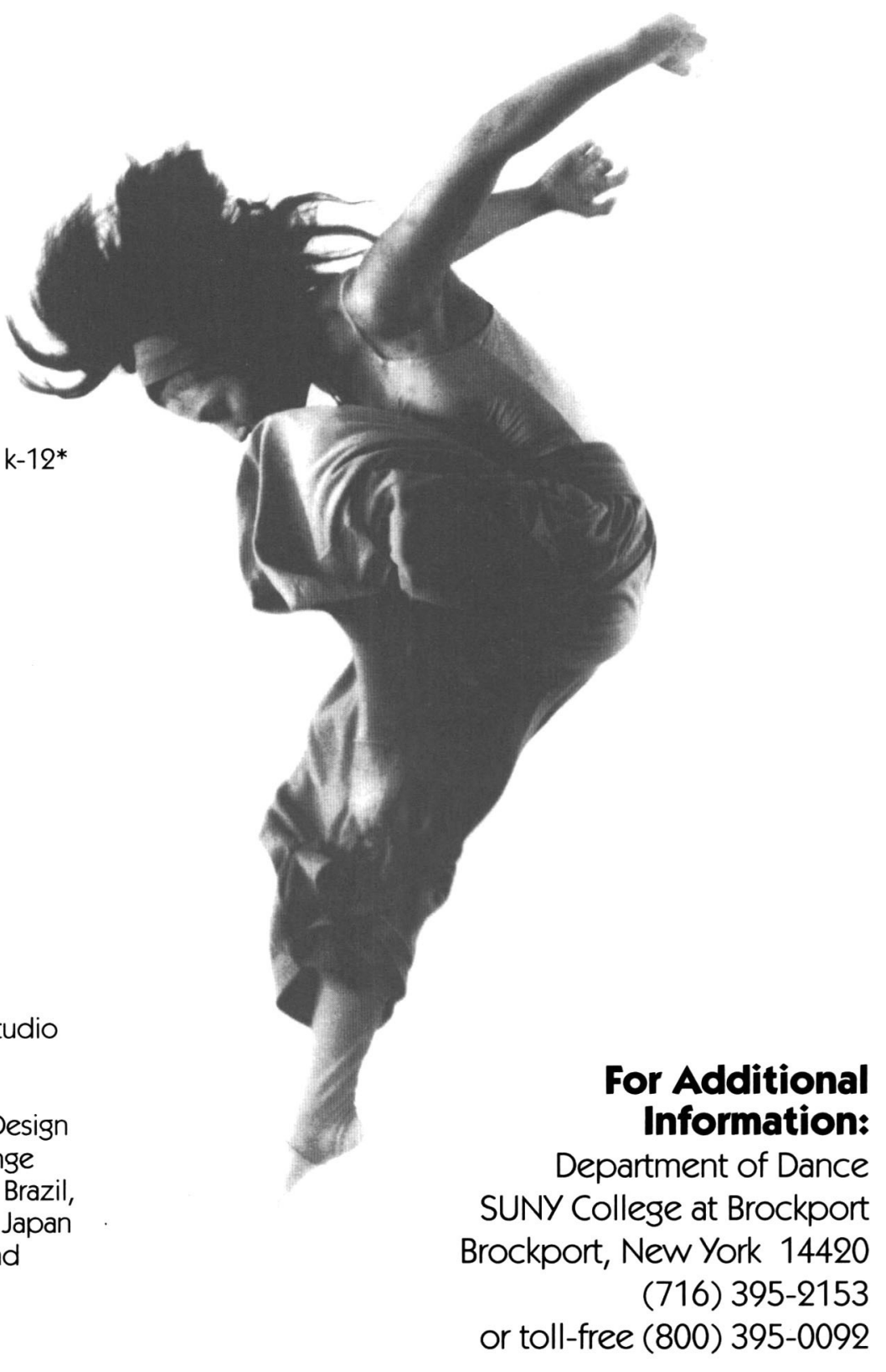


The Congress on Research in Dance (CORD) is an interdisciplinary organization with an open, international membership. Its purposes are 1) to encourage research in all aspects of dance, including its related fields; 2) to foster the exchange of ideas, resources, and methodology through publications, international and regional conferences, and workshops; 3 ) to promote the accessibility of research materials.

CORD is a non-profit, tax-exempt organization. Copies of the CORD financial and operating report, filed with the State of New York, are available upon written request from the New York State Board of Social Welfare, Charities Registration Section, Office Tower, Empire State Plaza, Albany, NY 12242 U.S.A.

Members of CORD have voting privileges, reduced rates at conferences, and special discounts on publica- tions, and receive two journals and two newsletters each membership year, which extends from January 1 to December 31. Members whose dues are received in the CORD Office after March 15 will receive current publications unless no stock remains, in which case they will receive another recent issue. (Publication print-runs are based on current membership figures and include a limited number of over-runs projected to accommodate members who join after March 15.) To ensure receipt of publications, members are responsible for notifying the CORD Office of address changes in a timely manner.

Membership Fees are given below in U.S. dollars, and must be paid in U.S. funds in the form of a check drawn on a U.S. bank, international money order, or international postal money order:

\begin{tabular}{|c|c|c|}
\hline North America (USA, Canada, $\mathbf{N}$ & (ico) & Outside North America \\
\hline 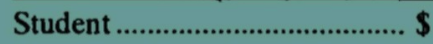 & 30 & 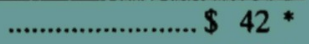 \\
\hline 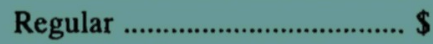 & 60 & 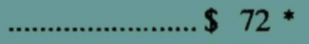 \\
\hline Institutional .......................... \$ & 72 & 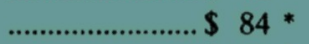 \\
\hline Retired & 30 & $\ldots 42^{*}$ \\
\hline 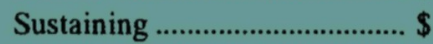 & $50^{* *}$ & \\
\hline Friend & $60^{* *}$ & \\
\hline Donor & $100^{* *}$ & \\
\hline Sponsor & $500^{* *}$ & \\
\hline Patron & $000^{* *}$ & \\
\hline
\end{tabular}

\section{Executive Committee}

Ann Hamilton Dils-President, Susan SpaldingPast President, Karen Bradley-President-Elect, Elsa Posey-Treasurer, Helen Chadima-Recording Secretary, Loren Bucek-Finance Chair, Thomas Hagood-Membership Chair, Naima Prevots-Editorial Board Chair

\section{Board of Directors}

Ann Kipling Brown, Mary Edsall, Joan Frosch, Veta Goler, John Perpener III, Rosalind Pierson, Anthony Shay, Jan Van Dyke, Judy Van Zile, Yunyu Wang, Jin-Wen $\mathrm{Yu}$

\section{Newsletter Editor}

Linda James

\section{Office Administrator Kista Tucker}

Computer layout design: Anita Focht, Franklin \& Marshall College Proofreading Assistant: Beth Pomerantz

\section{Editorial Board}

Rima Faber-Chair, Ananya, Lynn Brooks, Uttara Coorlawala, Sharon Friedler, Susan Glazer, Linda James, Janice LaPointe-Crump, Joellen Meglin, Nancy Stokes

Dance Research Journal is indexed in Arts and Humanities Citation Index; Current Contents: Arts and Humanities; Dance: Current Awareness Bulletin; Expanded Academic Index; Humanities Index; Index to Dance Periodicals; Physical Education Index; Ebsco Publishing. 